\title{
Evidence for Insulin Degradation by Muscle and Fat Tissue in an Insulin Resistant Diabetic Patient
}

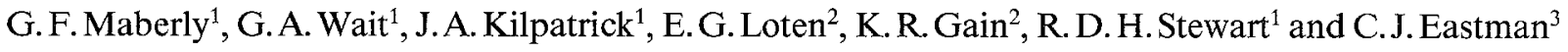 \\ Departments of ${ }^{1}$ Medicine and ${ }^{2}$ Clinical Biochemistry, University of Otago, Dunedin, New Zealand and ${ }^{3}$ Department of Medicine, \\ Westmead Centre Westmead, New South Wales, Australia
}

\begin{abstract}
Summary. The period before, during and after resistance to subcutaneous insulin in a 20-year-old, non-obese insulin-dependent patient with 'brittle' diabetes is documented and clinical observations are correlated with experimental results of insulin degradation in vitro. Treatment with intravenous but not subcutaneous aprotinin markedly reduced subcutaneous insulin requirements. Insulin resistance recurred following cessation of aprotinin. Serum free insulin levels were low during the subcutaneous resistant phase compared with those during the more sensitive phase. Insulin degradation in vitro by adipose tissue and muscle taken from the patient during a resistant
\end{abstract}

phase was increased compared with degradation by tissue taken during a sensitive phase and by tissue from normal subjects. Chromatography of incubation media revealed that during the resistant phase, tissue from the patient degraded insulin to small fragments. It is concluded that, in this patient, insulin resistance was caused by excessive degradation in both muscle and adipose tissue.

Key words: Insulin resistance, insulin degradation, diabetes mellitus, aprotinin, insulinases.
The degradation of insulin and other peptide hormones by proteolytic enzymes and its inhibition by protease inhibitors have both been studied extensively [1-24]. In several species, diminished effectiveness of insulin administered subcutaneously has been attributed to increased degradation by adipose tissue [25-28]. Moreover, insulin resistance in certain diabetic patients has been attributed to excessive degradation of administered insulin at the injection site [15-22], in serum [17, 23] or in more central tissues [24]. Aprotinin, a proteinase inhibitor, has been beneficial in some of these patients $[19,21$, $24,25]$.

We report a diabetic patient who developed insensitivity to insulin injected subcutaneously but not intravenously. Clinical and laboratory studies showed that insulin resistance was due to excessive insulin degradation in adipose and muscle tissue and could be reversed by aprotinin.

\section{Methods \\ Clinical Data}

A 20-year-old insulin-dependent diabetic female, weighing $55 \mathrm{~kg}$, was admitted with uncontrolled diabetes to Dunedin Hospital in April, 1980. An admission for ketoacidosis 2 months previously had been precipitated by a urinary tract infection, complicated by bilateral renal abscesses. Insulin requirements had increased from $30 \mathrm{U} /$ day in March 1980 to $132 \mathrm{U} /$ day at the time of admission. Obesity, underlying infec- tion and rebound hyperglycaemia were excluded as causes for the insulin insensitivity. Because hourly SC insulin supplements of 4-10 U failed to control plasma glucose levels, continuous IV insulin infusion was commenced. Plasma glucose levels fell to normal within $2 \mathrm{~h}$ and were maintained between 8 and $24 \mathrm{mmol} / 1$ by infusion rates of 1-4 U/h. Reinstitution of SC insulin caused reversion to insulin insensitivity with large doses ( $>200 \mathrm{U} /$ day) being required to prevent ketoacidosis.

Intravenous administration of aprotinin $(200,000$ Kallikrein Inactivator Units (KIU) over a period of $30 \mathrm{~min}$ ) caused a fall in plasma glucose from 12 to $1.5 \mathrm{mmol} / 1$ within $15 \mathrm{~min}$, necessitating IV glucose supplements. Maintenance therapy with IV aprotinin 200,000 KIU every $8 \mathrm{~h}$ reduced SC insulin requirements to $30-55 \mathrm{U} / \mathrm{day}$, but discontinuation resulted in a recurrence of insulin insensitivity. The addition of aprotinin $(5,000 \mathrm{KIU})$ to $\mathrm{SC}$ insulin injections was ineffective. Neither continuous SC insulin administration by an infusion pump (Mill Hill, London, UK) nor intermittent IM injections reduced insulin requirements significantly but glycaemic control was achieved with $50 \mathrm{U} /$ day administered by continuous IM infusion.

After 2 months of the latter treatment, $\mathrm{SC}$ insulin sensitivity to depot injection was regained with requirements of 50-60 U/day.

However, in January 1981 she was re-admitted with hyperglycaemia, ketoacidosis and a urinary tract infection and was treated with IV insulin and antibiotics for 6 weeks. Since then she has maintained satisfactory control of her diabetes with twice daily SC insulin (50-60 U/day).

Adipose tissue and skeletal muscle biopsies were obtained under general anaesthesia during periods of insulin insensitivity while the patient was receiving $\mathrm{SC}$ insulin and after a prolonged period of good control with IV insulin. Further samples were obtained during elective cholecystectomy in June 1981, when satisfactory glycaemic control was being maintained with 50-60 U/day SC. Informed consent was obtained from the patient for all procedures. 
Table 1. Total and free serum insulin in the patient at various times during her illness

\begin{tabular}{|c|c|c|c|c|}
\hline $\begin{array}{l}\text { Total } \\
\text { insulin } \\
\text { dose } \\
(\mathrm{U} / 24 \mathrm{~h})\end{array}$ & $\begin{array}{l}\text { Last } \\
\text { insulin } \\
\text { dose }\end{array}$ & $\begin{array}{l}\text { Time before } \\
\text { sampling, of } \\
\text { last dose } \\
\text { (h) }\end{array}$ & $\begin{array}{l}\text { Total serum } \\
\text { insulin } \\
(\mathrm{pmol} / 1)\end{array}$ & $\begin{array}{l}\text { Free serum } \\
\text { insulin } \\
(\mathrm{pmol} / \mathrm{l})\end{array}$ \\
\hline $230 \mathrm{SC}$ & $30 \mathrm{U}$ & 1 & 17 & 9 \\
\hline $125 \mathrm{SC}$ & $10 \mathrm{U}$ & 2 & 48 & 25 \\
\hline $100 \mathrm{SC}$ & $20 \mathrm{U}$ & 4 & 70 & 43 \\
\hline $100 \mathrm{SC}$ & $30 \mathrm{U}$ & 1 & 372 & 239 \\
\hline $54 \mathrm{SC}$ & $30 \mathrm{U}$ & 4 & 88 & 54 \\
\hline 34 IV & $2 \mathrm{U} / \mathrm{h}$ & continuous & 628 & 424 \\
\hline 24 IV & $0.5 \mathrm{U} / \mathrm{h}$ & continuous & 42 & 24 \\
\hline
\end{tabular}

Table 2. Insulin degradation during incubation with tissue samples from the patient and from normal subjects

Insulin degraded

(fmol-h-1 $\cdot \mathrm{mg}$

protein $^{-1}$ ) (measured by

TCA precipitation)

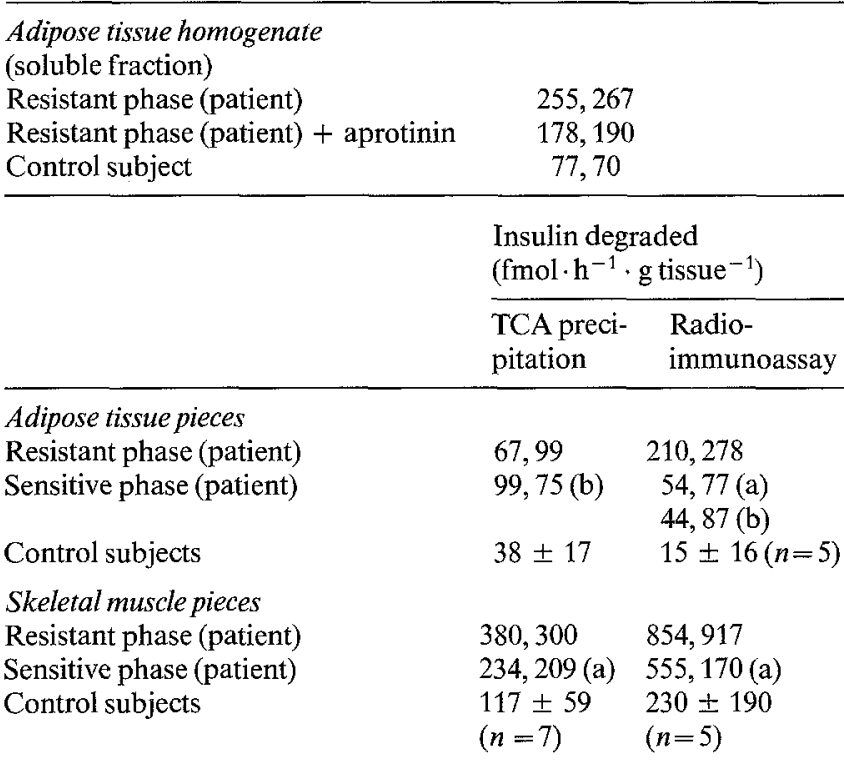

Values for the patient are results of duplicate determinations on a single tissue sample. Values for the control group are mean $\pm \operatorname{SD}(n=$ number of subjects tested). Adipose tissue samples (a) and (b) were obtained on separate occasions

\section{Laboratory Methods}

Samples of adipose tissue and skeletal muscle for use as controls were obtained from seven normal subjects undergoing orthopaedic surgery. Insulin degrading activity was measured using homogenates of adipose tissue or using pieces of either adipose tissue or muscle.

For the former experiments, a slight modification of the method of Paulsen et al. [17] was used. Tissue was homogenized in six volumes of $0.05 \mathrm{~mol} / 1 \mathrm{Tris} / \mathrm{HCl}(\mathrm{pH} 7.0$ ) with $0.25 \mathrm{~mol} / 1$ sucrose, using a PotterElvejham teflon-glass homogenizer and centrifuged at $3,000 \times g$ for $10 \mathrm{~min}$ at $4^{\circ} \mathrm{C}$. The infranatant was then centrifuged at $48,000 \times \mathrm{g}$ for $30 \mathrm{~min}$ at $4^{\circ} \mathrm{C}$. Insulin degrading activity was assayed in both soluble (supernatant) and particulate (pellet resuspended in the original volume of buffer) fractions by incubation in a shaking water bath at $37^{\circ} \mathrm{C}$ with $1,000 \mathrm{pmol} / \mathrm{l}$ insulin and tracer ${ }^{125} \mathrm{I}$-insulin $(30 \mathrm{pmol} / \mathrm{l})$ in the presence of $0.5 \%$ bovine serum albumin (Sigma Chemical Company, St. Louis, Missouri, USA). Aliquots $(200 \mu 1)$ were taken at $0,10,30$ and $60 \mathrm{~min}$ and added to $1 \mathrm{ml}$ ice-cold $10 \%$ trichloracetic acid (TCA). After centrifugation at $2,000 \times g$ for $15 \mathrm{~min}$, the supernatant was counted to determine the fraction of ${ }^{125} \mathrm{I}$ released by degradation of tracer insulin. The protein content of each tissue fraction was measured by the method of Lowry et al. [30]. When aprotinin was used in these incubations, the concentration was $10,000 \mathrm{KIU}$. The same procedure was used to measure insulin degradation in serum.

For the measurement of insulin degrading activity in tissue pieces, samples were placed in ice-cold Krebs-Ringer buffered with $25 \mathrm{mmol} / 1$ Hepes (4-(2-hydroxyethyl)-1-piper-azine-ethansulphonic acid) containing 3\% human serum albumin (Commonwealth Serum Laboratories, Melbourne), washed and cut into $0.2 \mathrm{~g}$ pieces. These were incubated with the above Krebs-Ringer buffer containing 100 $\mathrm{pmol} / \mathrm{l}$ insulin and tracer ${ }^{125}$ I-insulin $(30 \mathrm{pmol} / 1)$ in a shaking waterbath at $37^{\circ} \mathrm{C}$. Aliquots $(100 \mu \mathrm{l})$ were obtained at 0 and $60 \mathrm{~min}$ and added to trichloracetic acid as above. The remaining incubation media were stored at $-20^{\circ} \mathrm{C}$ and later applied to a $1.5 \times 90 \mathrm{~cm}$ column of Sephadex G-50 (medium grade, Pharmacia Fine Chemicals, Uppsala, Sweden) which was equilibrated and eluted with $0.1 \mathrm{~mol} / 1$ acetic acid. The eluted fractions were counted for ${ }^{125} \mathrm{I}$. Parallel incubations of tissue pieces without added ${ }^{125}$ I-insulin were carried out in the same manner, for the measurement of the degradation of immunoreactive insulin in the incubation medium, using radioimmunoassay [31]. Serial sampling confirmed that in all experiments insulin degradation was linear for at least $1 \mathrm{~h}$.

Porcine insulin (Eli Lilly, Indianapolis, USA) was iodinated by the method of Hunter and Greenwood [32] using $\mathrm{Na}^{125} \mathrm{I}$ from the Radiochemical Centre, Amersham, UK. A specific activity of $200 \mathrm{uCI} / \mathrm{ug}$ was obtained routinely. Before use the ${ }^{125} \mathrm{I}$-insulin was purified on a $1 \times 30 \mathrm{~cm}$ column of Sephadex G-75 (medium grade, Pharmacia) equilibrated and eluted with $0.01 \mathrm{~mol} / 1$ barbitone $/ \mathrm{HCl}(\mathrm{pH} 8.6)$. Human insulin standards (WHO 66/304, Mill Hill, London, UK) were used. Guinea pig anti-insulin serum was obtained from BurroughsWellcome (lot K6440) and used at a dilution of 1/45000. Total and free immunoreactive insulin in the patient's serum were measured by the method of Nakagawa et al. [33].

\section{Results}

Serum concentrations of total and free immunoreactive insulin at times when the patient was requiring different amounts of SC or IV insulin are shown in Table 1.

The soluble fraction of homogenate prepared from the patient's adipose tissue degraded more insulin to trichloracetic acid-soluble fragments that did a similar fraction from a control subject (Table 2). This increased degradation was partly inhibited by aprotinin. The particulate fraction of adipose tissue homogenate from both patient and control degraded much less insulin than did the soluble fraction and there was no difference between them. Serum samples from the patient, another diabetic patient and a non-diabetic control degraded less than $2 \%$ of the added insulin in $2 \mathrm{~h}$; there were no differences between them.

Adipose tissue pieces obtained from the patient during a SC insulin-resistant phase degraded more insulin than those obtained during the sensitive phase as assessed by disappearance of immunoreactive insulin, but this difference was not evident when degradation was measured by the formation of TCA-soluble ${ }^{125} \mathrm{I}$-insulin fragments. Muscle tissue obtained from the patient in an insulin resistant phase degraded more insulin than during the sensitive phase whether assessed by TCA precipitation or radioimmunoassay. In all cases, the amounts of insulin degraded by tissues obtained from the patient in an insulin resistant phase were more than two standard 
deviations greater than the mean obtained for the control subjects (Table 2).

When incubates of adipose tissue or skeletal muscle from three control subjects were chromatographed on Sephadex G-50 most of the radioactivity co-migrated with ${ }^{125}$ I-insulin (Fig. 1). Incubation of tissues obtained from the patient during a SC insulin-resistant phase had less radioactivity co-migrating with ${ }^{125}$ I-insulin, but substantial amounts appeared later in the elution along with smaller molecular weight compounds.

This difference was much less evident in the elution pattern of the incubate of muscle obtained from the patient in a SC insulin-sensitive phase and not apparent in that of the incubate of adipose tissue obtained on the same occasion.

\section{Discussion}

The case reported describes a young insulin-dependent patient who developed 'brittle' diabetes characterized by resistance to SC injected insulin. During the one-year period of SC insulin insensitivity, the patient was ketosis prone with considerable day-to-day variation of her insulin requirement making management difficult. IV insulin sensitivity was maintained throughout, permitting rapid control of hyperglycaemia and ketosis. Whereas serum free insulin levels were low in response to high dose SC therapy, they were appropriate during IV therapy and after recovery. IV aprotinin markedly reduced the concurrent requirement for $\mathrm{SC}$ insulin and there was a considerable reduction in insulin requirements on the days following prolonged treatment with either IV insulin or IV aprotinin. In contrast, single day infusion of insulin or aprotinin made no obvious impact on the SC insulin requirement on subsequent days.

Experiments in vitro demonstrated that, during an insulin-resistant phase, the patient's tissues were degrading insulin at an abnormally rapid rate. Incubation of ${ }^{125}$ I-insulin with the soluble fraction from adipose tissue homogenate clearly demonstrated a higher rate of degradation in the patient's tissue compared with that from a normal control, as also reported by Paulsen et al. [17]. Similarly pieces of muscle or adipose tissue obtained during a SC insulin-resistant phase degraded considerably more insulin than did corresponding tissues from control subjects. The results for the patient's tissues in a SC insulin-sensitive phase were generally intermediate.

The higher values for insulin degradation measured by radioimmunoassay than by release of TCA-soluble fragments probably indicates that some ${ }^{125} \mathrm{I}$-insulin fragments which no longer bind to specific antibody may still be precipitated with TCA. During the SC insulin-resistant phase muscle from our patient degraded insulin more rapidly than did adipose tissue. Such rapid degradation of insulin by muscle in patients with insulin resistance has not, to our knowledge, been reported.

Column chromatography of the incubation media using tissues obtained from the patient during an insulin-
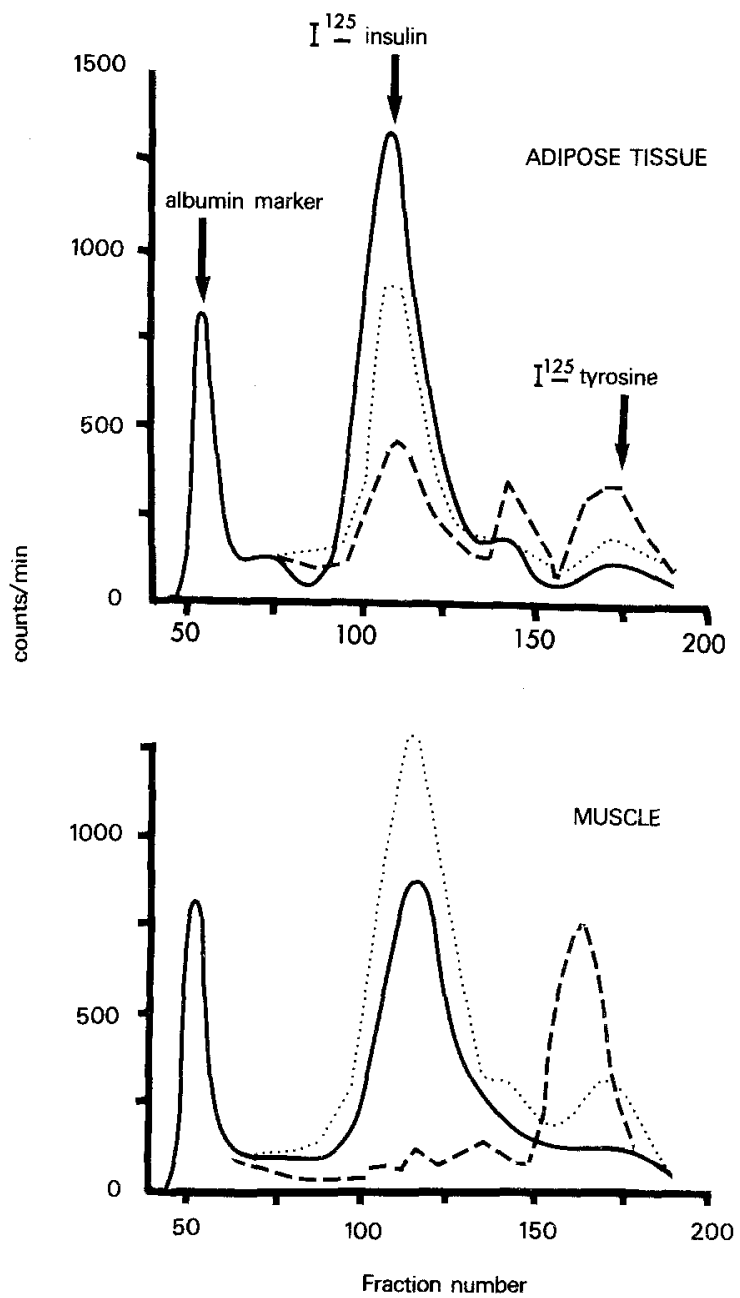

Fig. 1. Chromatography of the incubation media of insulin and tissue from the patient during SC-insulin sensitive $(. \ldots \ldots)$ and resistant $(---)$ phases and from normal subjects (__ _ . Albumin marker indicating void volume is shown only for control subjects. The column had previously been calibrated for ${ }^{125}$ I-insulin and ${ }^{125} \mathrm{I}$-tyrosine. The amounts of radioactivity applied in the different experiments were not comparable.

resistant phase showed much of the radioactivity eluted after intact insulin with a major peak at the iodotyrosine position. This suggests that, during the insulin-resistant phase, the patient's tissues were degrading insulin to small peptides and free amino acids. Such insulin degradation in various tissues has been reported by other investigators $[2,4,13,14,16]$. A small intermediate peak in our chromatograms may represent insulin A chain and suggest the involvement of insulin-glutathione transhydrogenase in insulin breakdown. It has been suggested that specific enzymes initiate the cleavage, allowing non-specific proteases access to complete the degradation [2].

In the diabetic, accelerated insulin degradation appears to have a spectrum of manifestations involving different tissues [15-24] and widely differing rates of insulin degradation. Recently Pickup et al. [22] reported the restoration of glycaemic control in five of six such patients following a period of continuous IM insulin infusion 
whereas SC infusion was ineffective, as in our patient. They suggested that insulin degradation in these patients may be bypassed by the IM route. This explanation is clearly inconsistent with our finding of muscle degrading insulin more rapidly than adipose tissue. An alternative explanation could be that absorption occurs more quickly than degradation, when insulin is administered by continuous IM infusion.

In this case of 'brittle' diabetes we have documented the period before, during and after SC resistance and demonstrated a correlation between the clinical observations and experimental results in vitro. It is not known how this generalized process of fat and muscle degradation of insulin is initiated. The period of insulin resistance in this patient appeared to commence following an infection, as has been reported in other cases [15, 21], and ultimate recovery followed a long course of IV antibiotics. We also observed periods of temporary improvement in SC insulin sensitivity following prolonged continuous IV or IM insulin infusion, suggesting that depot $\mathrm{SC}$ insulin may induce its own insulinase. Full understanding of these phenomena awaits further investigation.

Acknowledgements. For part of the time during this study, G. F. Maberly was supported by the National Health and Medical Research Council of Australia.

\section{References}

1. Mirsky IA, Broh-Kahn RH (1949) The inactivation of insulin by tissue extracts. 1. The distribution and properties of insulin inactivating extracts (insulinase). Arch Biochem 20:1-9

2. Thomas JH (1973) The role of "insulinase in the degradation of in sulin. Postgrad Med J (Suppl) 49:940-944

3. Varandani PT (1973) Insulin-degradation IV Sequential degradation of insulin by rat kidney, heart and skeletal muscle homogenates. Biochem Biophys Acta 295: 630-636

4. Terris S, Steiner DF (1975) Binding and degradation of $\mathrm{I}^{125}$ insulin by rat hepatocytes. J Biol Chem 250:8389-8398

5. Hammond JM, Jarett L (1975) Insulin degradation by isolated fat cells and their subcellular fraction. Diabetes 24: 1011-1019

6. Duckworth WC, Heinemann M, Kitabchi AE (1976) Proteolytic degradation of insulin and glucagon. Biochem Biophys Acta 377: 421-430

7. Parsons JA, Rafferty B, Stevenson RW, Zanelli JM (1977) Use of protease inhibitors to protect subcutaneously injected peptide hormones against local degradation. Br J Pharmacol 59:489-490

8. Stevenson RW, Tsakok TI, Parsons JA (1978) Partial inactivation of insulin injected or infused subcutaneously to rats. Diabetologia 15: 272 (Abstract)

9. Offord RE, Philippe J, Davies JG, Halbon PA, Berger M (1979) The inhibition of degradation of insulin by ophthalmic acid and a bovine pancreatic protease inhibitor. Biochem J 182: 249-251

10. Duckworth WC, Gifford D, Kitabchi AE, Runyan K, Solomon S (1979) Insulin binding and degradation by muscles from streptozotocin-diabetic rats. Diabetes 28: 746-748

11. Yokono K, Imamura Y, Sakai H, Baba S (1979) Insulin-degrading activity of plasma membranes from rat skeletal muscle - its isolation, characterisation and biologic significance. Diabetes 28: 810-817

12. Parsons JA, Rafferty B, Stevenson RW, Zanelli JM (1979) Evidence that protease inhibitors reduce degradation of parathyroid hormone and calcitonin injected subcutaneously. Br J Pharmacol 66: $25-32$
13. Yokono K, Imamura Y, Shii K, Mizuno N, Sakai H, Baba S (1980) Immunochemical studies on the insulin-degrading enzyme from pig and rat skeletal muscle. Diabetes 29:856-859

14. Yokono K, Imamura Y, Shii K, Sakai H, Baba S (1981) Purification and characterization of insulin-degrading enzyme from pig skeletal muscle. Endocrinology 108:1527-1532

15. Paulsen EP (1976) An insulin-degrading enzyme in a diabetic girl causing massive destruction of subcutaneous insulin. Diabetes 25: 334 (Abstract)

16. Dandona P, Foster M, Healey F, Greenbury E, Beckett AG (1978) Low-dose insulin infusions in diabetic patients with high insulin requirements. Lancet 2: 283-285

17. Paulsen EP, Courtney JW, Duckworth WC (1979) Insulin resistance caused by massive degradation of subcutaneous insulin. Diabetes $28: 640-645$

18. Kitabchi AE, Stentz FB, Cole C, Duckworth WC (1979) Accelerated insulin degradation: an alternative mechanism for insulin resistance. Diabetes Care 2: 414-417

19. Freidenberg G, White N, Cataland S, O'Dorisio T, Sotos J, Santiago J (1980) Effectiveness of aprotinin (Trasylol) in protease mediated insulin resistance. Diabetes 29 (Suppl 2): 23A (Abstract)

20. Pickup JC, Bilous RW, Keen H (1980) Aprotinin and insulin resistance. Lancet 2:93-94

21. Müller WA, Taillens C, Léreret S, Berger M, Philippe J, Halban PA, Offord RE (1980) Resistance against subcutaneous insulin successfully managed with aprotinin. Lancet 1:1245-1246

22. Pickup JC, Home PD, Bilous RW, Keen H, Alberti KGMM(1981) Management of severely brittle diabetes by continuous subcutaneous and intramuscular insulin infusions: evidence for a defect in subcutaneous insulin absorption. Br Med J 282:347-350

23. Misbin RI, Almira EC, Cleman MW (1981) Insulin degradation in the serum of a patient with apparent insulin resistance J Clin Endocrinol Metab 52:177-180

24. McElduff A, Eastman CJ, Haynes SP, Bowen KM (1980) Apparent insulin resistance due to abnormal enzymatic insulin degradation: a new mechanism for insulin resistance. Aust NZ J Med 10: 56-61

25. Guerra SMO, Kitabchi AE (1976) Comparison of the effectiveness of various routes of insulin injections : insulin levels and glucose response in normal subjects. J Clin Endocrinol Metab 42:869-874

26. Stevenson RW, Tsakok TI, Parsons JA (1980) Matched glucose response to insulin administered subcutaneously and intravenously. Evidence for subcutaneous inactivation of insulin. Diabetologia $18: 423-426$

27. Berger M, Halban PA, Muller WA, Offord RE, Renold AE, Vranic M (1978) Mobilisation of subcutaneously injected tritiated insulin in rats: effects of muscular exercise. Diabetologia 15:133-140

28. Berger M, Halban PA, Girardier L, Seydoux J, Offord RE, Renold AE (1979) Absorption kinetics of subcutaneously injected insulin. Evidence for degradation at the injection site. Diabetologia 17: 97-90

30. Lowry OH, Rosebrough NJ, Farr AL, Randle RJ (1951) Protein measurement with the folin phenol reagent. J Biol Chem 193: 265-275

31. Desbuquois S, Auerbach GD (1971) Use of polyethylene glycol to separate free and antibody bound peptide hormones in RIA. J Clin Endocrinol 33:732-738

32. Hunter WM, Greenwood FE (1962) Preparation of iodine-131 labelled human growth hormone of high specific activity. Nature (Lond) 194: 495-496

33. Nakagawa S, N Nakayama H, Saski T, Yoshino K, Yu YY, Shinozaki K, Aoki S, Mashimo K (1973) A simple method for the determination of serum free insulin levels in insulin treated patients. Diabetes 22: 590-600

Received : 29 September 1981

and in revised form: 2 June 1982

Dr. G.F. Maberly

Endocrine Unit

Department of Medicine

Westmead Centre

Westmead, NSW 2145, Australia 